\title{
THE REPROACH OF PSYCHIATRY IN ENGLAND.
}

OF all the branches of medicine psychiatry seems still to suffer from that relative neglect and to labour under those disadvantages which tradition assigns to the lot of the youngest sister. From time to time the calm of apparent stagnation is ruffled by some breeze of public agitation seeking to direct attention to defects, administrative or otherwise, yet such superficial disturbance bears little proportion to the immense undercurrent of dissatisfaction running strongly, within the profession itself, in the minds of all who have the interests of psychiatry in England at heart. If we inquire the reasons of this they are found to reside in a combination of factors on which stress has been laid repeatedly, with as yet little obvious result. It is imperative that the fons et origo of the dissatisfaction, which percolates through all the strata of asylum life, should be clearly laid bare, else the stream will continue to run muddily. It will, we believe, be granted that the scientific health of the asylum unit-that is, of the medical staff-takes its tone from the superintendent; should he be keen on the advancement of psychiatric learning, his subordinates find themselves in a stimulating atmosphere, the influence of which is reflected in the actual treatment of the inmates, as well as in the contributions from the staff to the body of psychiatric doctrine. On the other hand, if the senior has been selected more for social than for scientific equipment, or should he allow himself to be more concerned with the asylum laundry or meatsupply than with the healing of the mind, not only is the general scientific level of the institution lowered, but any junior medical officer is only too apt to find his youthful enthusiasm starved in an uncongenial environment; he sinks to the humdrum level of those with whom he is inevitably in such close association. The asylum officer who can rise superior to depressing surroundings is the exception. We should be the last to belittle the importance of social and administrative gifts in the smooth running of the asylum communities of the country, which from their very nature must be self-contained and self-sufficient, but psychiatry exists as a branch of medicine for the prevention and cure of mental disease, and nothing can ever be permitted to usurp this function. No elaborate schemes of internal decoration, no ingenuity of kitchen appliances, no perfectly fitted miniature theatres or admirably supplied gardens, farms and piggeries, can make up for indifference to clinical and pathological reports, neglect of modern technique in treatment, or absence of stimulus to increase the annual percentage of cures or relief.

The promotion or advancement of a medical officer, further, sometimes seems to depend so little on his professional knowledge that he has scant inducement to devote himself to an earnest study of the subject. His work is too often seen to begin and end with the discharge of routine-essential duties which fatigue without stimulating - and with the accomplishment of which any incentive to personal research vanishes. When he has time to think over things he fully realises the tremendous material at his disposal, the fascination of the study of the complex case, the therapeutic problems with which he is surrounded, yet evening finds him unable or disinclined to sit down to serious work. There is, however, another reason for the paucity of scientific output. Friendly conversation with the average asylum medical officer has often elicited the confession that he does not know how or where to begin his task; he is conscious of not being abreast of knowledge in many instances, and is sorely in lack of a guiding and advising mind. If this position be analysed it will be seen to derive from the fact that so few centres for the organised teaching of psychiatry exist, and the equipment of some leaves much to be desired. Of how many of our asylum officers can it be said that they have attended courses of theoretic and practical psychiatry at home or abroad? When do they get a four or six weeks' leave of absence to follow post-graduate instruction in their life's work at a recognised centre? Nay, how many of them have ever spent an unforgettable Wanderjahr in foreign school or laboratory prior to their entering on their professional career of psychiatric expert? Not that foreign experience of itself confers a cachet unobtainable at home, for our home material, in no way inferior, is calling out for investigation and research ; but as long as our young medical officers drift untrained into asylum work, so long will the reproach continue that in this country psychiatry is not adequately studied.

On other occasions we have spoken of the peculiar restrictions and handicaps of 
certain phases of asylum life for the junior staff; we are more concerned for the present to appeal emphatically for better chances for training, better facilities to keep abreast of scientific advance, greater endeavour to make the first step on the ladder encouraging, more serious efforts to utilise precious time and valuable stuff. Is it too much to hope that the authorities who control asylum affairs should one day claim a certain standard of professional attainment on the part of medical officers entering the service, and insist similarly on granting members of asylum staffs post-graduate leave? We are confident that the outlook is bright in reality, and that the stirring among what only the cynic would call the dry bones augurs well for the future. We can imagine a central authority fully conversant with the best methods employed in the whole range of the practice of psychiatry, and able to give local bodies information and guidance as to management, equipment, and expectation of output on the scientific side no less than on the others; we can foresee the day when prophylaxis and prevention will be elevated to their true importance by the establishment of clinics and observation wards staffed by trained men with all-round experience. The problem confronting us is the elaboration of the best way to organise and utilise the sources of psychiatric energy which, we are convinced, are only waiting to be tapped.-Lancet, March 6th, 1920.

\section{NURSES REGISTRATION ACT, 1919. ENGLAND AND WALES.(')}

\section{9 \& 10 Geo. 5, Ch. 94. 23rd December 1919.}

1.-(1) For the purposes of this Act, there shall be established a General Nursing Council for England and Wales (in this Act referred to as "the Council"), which shall be a body corporate by that name with perpetual succession and a common seal with power to acquire and hold land without licence in mortmain.

(2) The Council shall be constituted in accordance with the provisions contained in the Schedule to this Act.

(3) The seal of the Council shall be authenticated $n$ the prescribed manner and any document purporting to be sealed with the said seal so authenticated shall be receivable in evidence of the particulars stated in that document.

2. - (1) It shall be the duty of the Council to form and keep a register of nurses for the sick in this Act referred to as "the register") subject to and in accordance with the provisions of this Act.

(2) The register shall consist of the following parts:-(a) a general part containing the names of all nurses who satisfy the conditions of admission to that part of the register: $(b)$ a supplementary part containing the names of male nurses: (c) a supplementary part containing the names of nurses trained in the nursing and care of persons suffering from mental diseases: $(d)$ a supplementary part containing the names of nurses trained in the nursing of sick children: (e) any other prescribed part.

Where any person satisfies the conditions of admission to any supplementary or prescribed part of the register, his name may be included in that part of the register notwithstanding that it is also included in the general part.

(3) A certificate under the seal of the Council duly authenticated in the prescribed manner stating that any person is, or was at any date, or is not, or was not at any date, duly registered under this Act shall be conclusive evidence in all courts of law of the fact stated in the certificate.

(4) Any reference in this Act to the register shall, unless the context otherwise requires, be deemed to include a reference to any part of the register, and the expression " registered" shall be construed accordingly.

3.-(I) The Council shall make rules for the following purposes:-(a) for regulating the formation, maintenance and publication of the register; (b) for regulating the conditions of admission to the register; (c) for regulating the conduct of any examinations which may be prescribed as a condition of admission to the register, and any matters ancillary to or connected with any such examinations; (d) for prescribing the causes for which, the conditions under which, and the manner in which nurses may be removed from the register, the procedure for the restoration to the register of nurses who have been removed therefrom, and the fee to be payable on such restoration; (e) for regulating the summoning 